\title{
Combined Effect of Low-Level Laser Treatment and Levothyroxine on Wound Healing in Rats With Hypothyroidism
}

\author{
Amin Firouzi ${ }^{1}$, Mohsen Norozian ${ }^{2,3}$, Abdollah Amini ${ }^{2 *}$, Mohammad-Amin Abdollahifar ${ }^{2}$, Hojjat-Allah \\ Abbaszadeh', Fatemeh Fadaei Fathabadi ${ }^{2,3^{*}}$ \\ ${ }^{1}$ Medical School, Shahid Beheshti University of Medical Sciences, Tehran, Iran \\ ${ }^{2}$ Department of Biology and Anatomical Sciences, School of Medicine, Shahid Beheshti University of Medical Sciences, \\ Tehran, Iran \\ ${ }^{3}$ Laser Application in Medical Sciences Research Center, Shahid Beheshti University of Medical Sciences, Tehran, Iran
}

\section{*Correspondence to \\ Abdollah Amini, PhD; Associate professor, Department of Biology and Anatomical Sciences, School of Medicine, Shahid Beheshti \\ University of Medical Sciences, Tehran, Iran. Tel: +98 9126898452; Fax: +872122439976 \\ Email: d.amini2008@yahoo.com; Fatemeh Fadaei Fathabadi PhD; Associate professor, Department of Biology and Anatomical Sciences, School of Medicine, Shahid Beheshti University of Medical Sciences, Tehran, Iran. Tel: +98 9120067541; Fax: +87 2122439976; Email: Fatemehfadaeifathabadi@gmail.com}

Published online 17 September 2018

\section{Introduction}

Hypothyroidism is caused by insufficient thyroid hormone production. ${ }^{1}$ It is an endocrine condition ${ }^{2,3}$ with a prevalence in females that is 8 - to 10 -fold higher than in males. ${ }^{1}$ Hypothyroidism decreases metabolic and physiologic activity. Symptoms of this disease include changes in body weight and sleep patterns, decreased metabolism, growth and epithelial proliferation, and delayed wound healing. ${ }^{4}$

Side-effects of this condition are decreases in cellular metabolism and proliferation; thus, hypothyroidism becomes critical when the body requires high rates of cellular proliferation and metabolism. The skin of individuals with hypothyroidism is thin, rough and scaly. ${ }^{5}$ While wound healing depends on connective tissue activity and cellular proliferation, synthesis of connective tissue in the skin, such as collagen, and tissue tensile strength decrease in those with hypothyroidism. ${ }^{6}$

T3 in culture medium can induce fibroblast and keratinocyte proliferation. ${ }^{5}$ Wound healing is a complicated process that involves clot formation, inflammation, granulation, epithelialization, and remodeling. ${ }^{7,8}$ Studies on wound healing have investigated the effect of oxygen therapy, ${ }^{9-11}$ biomechanics, ${ }^{12}$ radiotherapy and medical pomades. ${ }^{13}$

Low-level laser therapy (LLLT) is a good modality for wound healing. ${ }^{14}$ Recent studies have revealed that LLLT has a stimulatory effect on the skin. Light absorbed by the mitochondrial chain can increase ATP synthesis, oxygen production, and protein synthesis as well as

Please cite this article as follows: Firouzi A, Norozian M, Amini A, Abdollahifar MA, Abbaszadeh HA, Fadaei Fathabadi F. Combined effect of low-level laser treatment and levothyroxine on wound healing in rats with hypothyroidism. J Lasers Med Sci. 2018;9(4):268-273. doi:10.15171/jlms.2018.48. 
induce mitotic cellular proliferation. ${ }^{15-17}$ LLLT decreases the inflammation phase and provides positive stimulation for the remodeling phase. It also increases fibroblast proliferation, tensile resistance, and collagen synthesis. LLLT increases synthesis of connective tissue in the primary phases of wound healing..$^{18,19}$

Studies show that LLLT in the early stage of wound healing in healthy and diabetic individual ${ }^{20,21}$ can increase the production of reactive oxygen species (ROS) in cells. A low rate of ROS production can cause activation of mitogenactivated protein kinase (MAPK) signaling pathways that halt proliferation and differentiation of cells. A high laser dose can increase ROS and disturbance of physiologic activity in cells..$^{22,23}$

Because levothyroxine has a high half-life of about 7 days, it is prescribed for hypothyroidism. Hormone replacement therapy has a better effect in hypothyroidism if zinc is added. ${ }^{24}$ Studies have shown that application of thyroid hormone pomades can accelerate wound healing and increase the number of hair follicles. ${ }^{25-27}$

The aim of this study was an investigation of the combined effect of LLLT (wavelength of $810 \mathrm{~nm}$, frequency of $80 \mathrm{~Hz}$, energy density of $0.2 \mathrm{~J} / \mathrm{cm}^{2}$ ) with the use of levothyroxine on the healing process of incisions in rats with hypothyroidism. The combined use of LLLT and levothyroxine could improve wound healing in patients with hypothyroidism.

\section{Methods}

Sixty adult male rats weighing 200-220 g were obtained from Pasteur Institute (Iran) and were kept at the Animal laboratory in the Anatomy Department. All animals were housed in separate cages and were maintained in a 12 hour light:dark cycle. The animals were provided a standard laboratory diet and water ad libitum.

The rats were divided into 5 groups and each group was divided into 3 subgroups containing 4 animals each for the evaluation of the treatment on days 4, 7 and 14 after wound creation. The groups were: (1) healthy controls; (2) controls with hypothyroidism alone; (3) hypothyroidism + laser treatment; (4) hypothyroidism + levothyroxine treatment; (5) hypothyroidism + laser + levothyroxine treatments.

Induction of Hypothyroidism

Hypothyroidism was induced in all groups except group 1 by the addition of $4 \mathrm{mg}$ of powdered methimazole in $100 \mathrm{~mL}$ of drinking water. The water was refreshed every day. After administration of intramuscular general anesthesia (ketamine $50 \mathrm{mg} / \mathrm{kg}$ and xylazine $20 \mathrm{mg} / \mathrm{kg}$ ), blood samples were collected from the corners of the eyes of the rats at 28 days after treatment with methimazole to confirm a diagnosis of hypothyroidism. For measurement of T3 and T4, blood serum was separated and assessed by commercial radioimmunoassay ELISA kits (DiaPlus; USA). Next, the animals were shaved on the dorsal ribcage and a standard incisional wound $(1.2 \mathrm{~cm})$ was created with a \#2 scalpel and was left without suturing or dressing. ${ }^{28}$

\section{Low-Level Laser Therapy}

The wounds in groups 3 and 5 were treated with a pulsed infrared diode laser with the following specifications:

- The highest power output: $75 \mathrm{~W}$

- Normal power: $1.08 \mathrm{~mW}$

- Energy density: $1.08 \mathrm{~mW} / \mathrm{cm}^{2}$

- Wavelength: $810 \mathrm{~nm}$

- The size of spot: $1 \mathrm{~cm}^{2}$

- The duration of each pulse: $180 \mathrm{~ns}$

- Each point of exposure duration: $200 \mathrm{~s}$

- The amount of energy density: $0.2 \mathrm{~J} / \mathrm{cm}^{2}$

The animals were sedated as described in the previous section. LLLT began directly after the incision surgery and was applied to 12 sections. These areas covered both the wound beds and the adjacent normal skin area. The probe was put into contact with the sample tissue. This procedure continued once a day every day except days 7 and 14 (in subgroups 7 and 14).

\section{Levothyroxine Therapy}

Treatment with levothyroxine started immediately after surgery and continued to the end of the procedure. Levothyroxine (Sigma, St. Louis, MO) administered at a dose of $20 \mu \mathrm{g} / \mathrm{kg} / \mathrm{d}$ i.p. ${ }^{12}$

\section{Tissue Preparation}

At the end of treatment, samples were taken from the lesions of the subgroups and were fixed in $10 \%$ formalin for 2 weeks. The solution was refreshed after the first 24 hours. The samples were prepared for sectioning using a tissue processor and then embedded in paraffin blocks and sectioned into $10 \mu \mathrm{m}$ sections with a microtome. The sections were stained with hematoxylin and eosin stain. To evaluate the healing of the wounds, stereological methods were used to count the number of basal cells, fibroblasts, and neutrophils, as well as to determine the volume of fibrous tissue. The stereological dissector method was applied to count the cells. Each harvested sample was assessed by $40 \times$ oil-immersion magnification in height numerical aperture.

Estimation of Volume of Epidermis, Dermis and Fibrous Tissue

To measure the total volume of epidermis, dermis, and collagen using the Cavalier's principle, the following formula was used:

\section{$V={ }^{\Sigma} P^{*} a / p^{*} t$}

Here the $t$ refers to the sampled sections distance. The $\Sigma \mathrm{P}$ is assessed by the point-counting way. The $a / p$ defined as the area related with each point projected on skin tissue. $^{1}$ 
Estimation of the number of fibroblasts, neutrophils, and basal cells

The fibroblast numbers, neutrophil, and basal cells were determined by the optical dissector technique. The locations of the microscopic fields were designated by an equal interval of moving the stage and systematic uniform random sampling. ${ }^{1,2}$ Microcator was used for measurement of $\mathrm{Z}$-axis movement of the microscope stage. An unbiased counting frame with inclusion and exclusion borders was superimposed on the images of the sections viewed on the monitor. A nucleus was counted if it was placed completely or partially within the counting frame and did not reach the exclusion line. Numerical density $(\mathrm{Nv})$ was calculated with the following formula: $\mathrm{Nv}=[\Sigma \mathrm{Q}-/(\mathrm{h} \times \mathrm{x}$ a $/ \mathrm{f} \times \Sigma \mathrm{p})] \times(\mathrm{t} / \mathrm{BA})$

where " $\Sigma \mathrm{Q}-$ " included the nuclei, numbers and " $\mathrm{h}$ " refers to the dissector height, " $\mathrm{a} / \mathrm{f}$ " is the area of frame, " $\Sigma \mathrm{P}$ " refers to the total number of the unbiased counting frame in each field, " $\mathrm{t}$ " is the actual thickness of sections evaluated in every field by the microcator, and BA refers to the advance of the block in microtome.

\section{Statistical Analysis}

The data collected was evaluated in SPSS 21 and was expressed as mean \pm SEM. To normalize the data, the Shapiro test was used. Statistical significance was considered at $P<0.05$ and was reported as mean \pm SEM.

\section{Results}

Overall Findings

Post-surgery, all the experimental rats were kept healthy and showed normal healing in the wound area without considerable infection. The rats with hypothyroidism recorded significantly lower T4 and T3 hormone levels than those in the euthyroid rats $(P=0.000)$. The T4 and T3 levels in the euthyroid rats were $3.80 \pm 0.15$ and $87.64 \pm 3.47 \mathrm{ng} / \mathrm{dL}$, respectively. In the rats with hypothyroidism, these were $1.322 \pm 0.07$ and $20.57 \pm 1.84$ $\mathrm{ng} / \mathrm{dl}$, respectively.

Volume of Epidermis, Dermis, Fibrous Tissue and Cell Density

To determine the volume of the epidermis, dermis and fibrous tissue and the cell density in wound healing, H\&E staining was used. The data between groups was collected by soteriological methods and normalized and measured as described below.

\section{Volume of Epidermis, Dermis and Fibrous Tissue}

To determine the volume of the epidermis, dermis and fibrous tissue, Cavalier's principle of the stereological method was used. ANOVA statistical methods were used for analysis. The analysis revealed that the best response was observed for the laser + levothyroxine groups. Figure 1 shows that the volume of the epidermis, dermis and fibrous tissue were significantly different in rats receiving

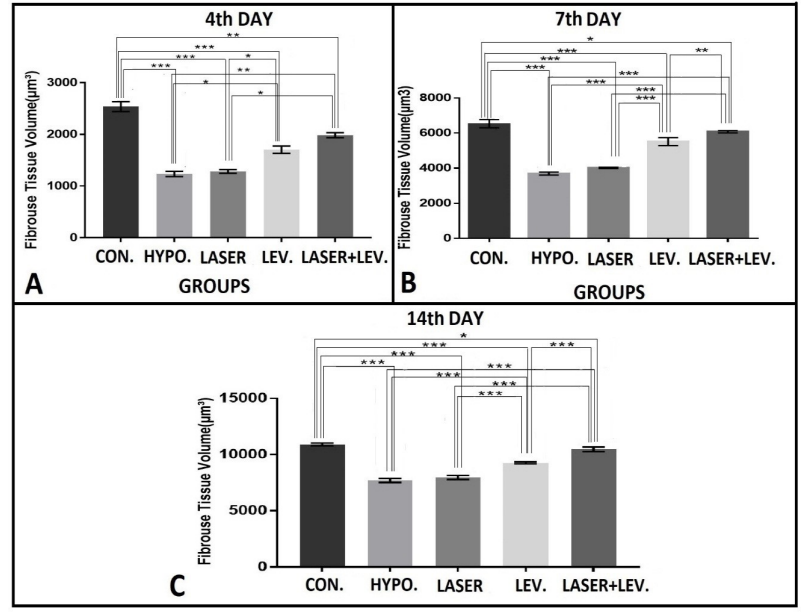

Figure 1. Mean of Fibrous Tissue Volume on 4th, 7th and 14th Day After Wound Creation. ${ }^{*} P<0.05 ;{ }^{* *} P<0.01 ; * * * P<0.001$

combined laser + levothyroxine when compared to groups 1-4. There was no significant increase in the volume of the epidermis, dermis and fibrous tissue in the laser groups but there was a significant difference in the levothyroxine group when compared with the hypothyroidism group. The volumes of the prefrontal cortex at days 4, 7 and 14 are shown in Figure 1.

\section{Number of Fibroblast Cells}

Figure 2 shows a decrease in fibroblast cell density and number of cells in the hypothyroidism group compared to the control group. The data also indicated that the number of cells in the group receiving laser + levothyroxine increased significantly when compared with the hypothyroidism, laser, and levothyroxine groups, but not the euthyroidic control group. The data obtained from the hypothyroidism and laser groups showed that there was no significant change in terms of fibroblast cell density between groups $(P>0.05)$.

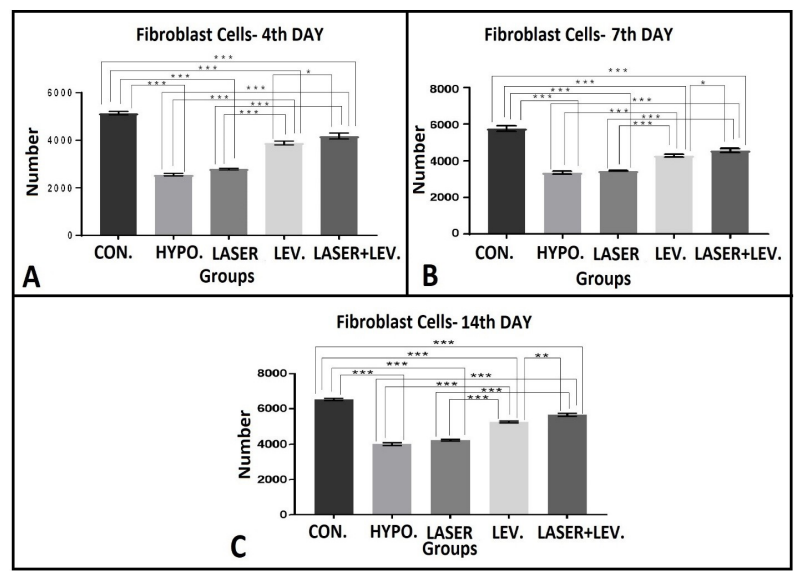

Figure 2. Mean of Fibroblast Cells Number on 4th, 7th and 14th Day After Wound Creation. ${ }^{*} P<0.05$; $* * P<0.01$; *** $P<0.001$. 


\section{Number of Neutrophil Cells}

As shown in Figure 3, the injection of levothyroxine into wounds receiving laser significantly reduced the number of neutrophils compared to the euthyroid control, laser and levothyroxine groups $(P<0.01)$. However, this decrease in the laser groups compared to the hypothyroidism groups was not significant. The difference in the decrease in the number of neutrophils in the levothyroxine group versus the other groups (control, laser, and hypothyroidism) was significant $(P<0.001)$.

\section{Number of Basal Cells}

Figure 4 shows that the basal cell density in the area of the wound of laser-treated rats increased dramatically following the levothyroxine injection $(P<0.001)$. The differences in numerical densities of the basal cells in the hypothyroidism groups and the laser-treated groups were not significant. The difference in the number of basal cells between the hypothyroidism and levothyroxine groups was statistically significant $(P<0.001)$. The results also indicated that combined laser + levothyroxine treatment increased the number of basal cells in comparison with the hypothyroidism, laser and levothyroxine groups; however, this increase was not significant when compared to the control group.

\section{Discussion}

The findings of the current study revealed that methimazole can induce hypothyroidism. Analysis of the data showed that fibrous tissue volume and the number of basal cells and fibroblasts increased, whereas the number of neutrophils decreased in subgroups 4, 7 and 14. Hypothyroidism is a prevalent endocrine disorder that effects the systems and metabolism of the body. One effect is a delay in wound healing. Studies show that the synthesis and organization of collagen fibers decrease in the presence of hypothyroidism. ${ }^{29}$ The healing of wounds is caused by the interaction of fibroblasts, myofibroblasts, endothelial cells and keratinocytes. ${ }^{30-32}$ Decreased secretion of thyroid hormones causes metabolic disorders and those related to the synthesis of collagen from inflammation to the proliferation phases.

The results of the current study are in parallel with earlier studies showing the adverse effects of hypothyroidism on wound healing. ${ }^{33}$ Methods for treatment of such wounds include hormone therapy, laser therapy, and pomades. Studies have shown that pomades that made from thyroxin hormone can accelerate the closure of wounds. ${ }^{25,26,34}$ The current study used the thyroxin hormone by direct application instead of topical administration. The results showed that administration of levothyroxine combined with laser treatment produced the best results.

The laser treatment did not improve fibrous tissue volume or the number of cells. Studies have shown that laser treatment alone has no effect on wound healing. Viegas et al and Busnardo et al showed that laser treatment

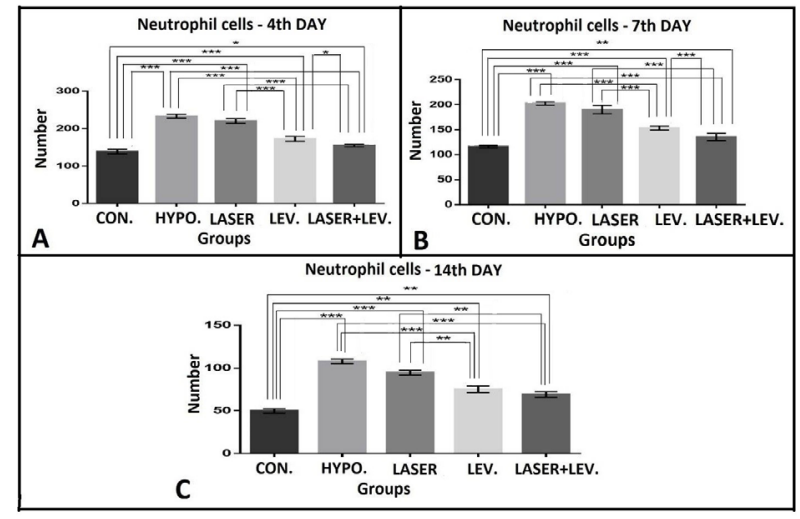

Figure 3. Mean of Neutrophil Cells Number on 4th, 7th and 14th Day After Wound Creation. ${ }^{*} P<0.05$; ${ }^{* *} P<0.01 ;{ }^{* * *} P<0.001$.

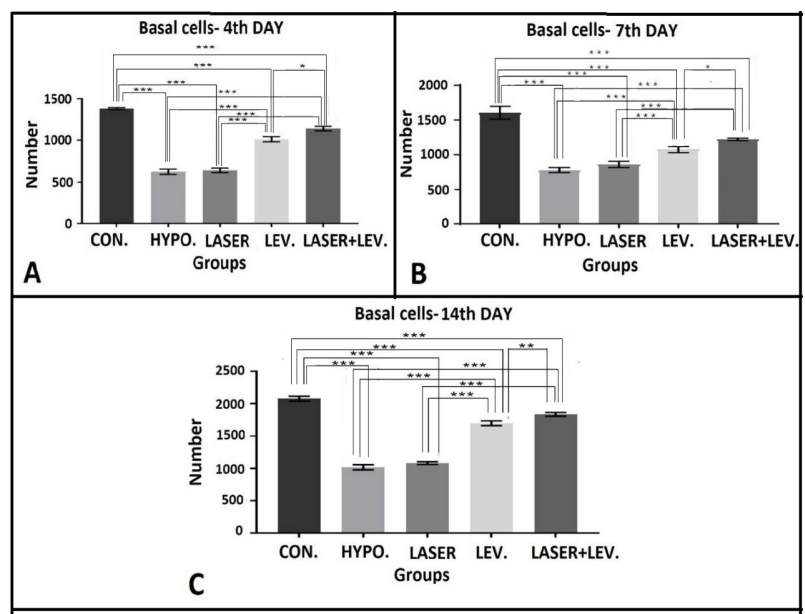

Figure 4. Mean \pm SEM of Number of Basal Cells on days 4,7 and 14 After Wound Creation. ${ }^{*} P<0.05$; ${ }^{* *} P<0.01$; ${ }^{* *} P<0.001$.

had no effect on the reduction of the inflammation phase. ${ }^{35,36}$ They improved their results using interleukin$1 \beta$. Allendorf et al found that the use of a He-Ne laser had no effect on wounds. ${ }^{37}$ This paradoxical investigation had no rules and no strong methods. The investigators used any wavelength, energy and power density that they concluded had the best effect on the skin.

The current study showed that laser treatment alone had no effect, but showed a positive effect when combined with levothyroxine. Hypothyroidism reduces the production of antioxidants, which increases ROS. An increase in oxidative stress in cells prolongs the inflammation phase and delays the proliferation phase. The administration of levothyroxine increased the antioxidants and decreased ROS. The proliferation phase began immediately when laser treatment increased cell proliferation. ${ }^{12,38}$

\section{Conclusion}

LLLT at $810 \mathrm{~nm}$ in wavelength, frequency of $80 \mathrm{~Hz}$ and energy density of $0.2 \mathrm{~J} / \mathrm{cm}^{2}$ combined with the application of levothyroxine significantly improved the histological properties of wounds in rats with hypothyroidism. 


\section{Conflict of Interests}

The authors don't have any conflict of interest.

\section{Ethical Considerations}

All procedures in these experiments were approved by the Ethics Committee of Shahid Beheshti Medical University.

\section{Acknowledgments}

We would like to thank Laser Application in Medical Sciences Research Center of Shahid Beheshti University of Medical Sciences for their support

\section{References}

1. Biondi B, Bartalena L, Chiovato L, et al. Recommendations for treatment of hypothyroidism with levothyroxine and levotriiodothyronine: a 2016 position statement of the Italian Society of Endocrinology and the Italian Thyroid Association. J Endocrinol Invest. 2016;39(12):1465-1474. doi:10.1007/s40618-016-0511-z

2. Canaris GJ, Manowitz NR, Mayor G, Ridgway EC. The Colorado thyroid disease prevalence study. Arch Intern Med. 2000;160(4):526-534.

3. Biondi B, Wartofsky L. Treatment With Thyroid Hormone. Endocr Rev. 2014;35(3):433-512. doi:10.1210/er.2013-1083

4. Sibilio A, Ambrosio R, Bonelli C, et al. Deiodination in cancer growth: the role of type III deiodinase. Minerva Endocrinol. 2012;37(4):315-327.

5. Safer JD. Thyroid hormone action on skin. Dermatoendocrinol. 2011;3(3):211-215. doi:10.4161/ derm.3.3.17027

6. Tha Nassif AC, Hintz Greca F, Graf H, Domingues Repka JC, Nassif LS. Wound healing in colonic anastomosis in hypothyroidism. Eur Surg Res. 2009;42(4):209-215. doi:10.1159/000208519

7. Paraguassu GM, da Guarda MG, Xavier FC, et al. Effects of LED phototherapy on relative wound contraction and reepithelialization during tissue repair in hypothyroid rats: morphometric and histological study. Lasers Med Sci. 2014;29(2):773-779. doi:10.1007/s10103-013-1419-X

8. Chehelcheraghi F, Eimani H, Homayoonsadraie S, et al. Effects of acellular amniotic membrane matrix and bone marrow-derived mesenchymal stem cells in improving random skin flap survival in rats. Iran Red Crescent Med J. 2016;18(6):e25588. doi:10.5812/ircmj.25588

9. Youn BA. Oxygen and its role in wound healing. J Invest Surg. 2001;14:221-225.

10. Fallahnezhad S, Piryaei A, Darbandi H, et al. Effect of low-level laser therapy and oxytocin on osteoporotic bone marrow-derived mesenchymal stem cells. J Cell Biochem. 2018;119(1):983-997. doi:10.1002/jcb.26265

11. Fallahnezhad S, Piryaei A, Tabeie F, et al. Low-level laser therapy with helium-neon laser improved viability of osteoporotic bone marrow-derived mesenchymal stem cells from ovariectomy-induced osteoporotic rats. J Biomed Opt. 2016;21(9):98002. doi:10.1117/1.jbo.21.9.098002

12. Firouzi A, Fadaei Fathabadi F, Norozian M, Amini A, Abdollahifar MA, Noruzian M. The combined effects of levothyroxine and low level laser therapy on wound healing in hypothyroidism male rat model. J Lasers Med
Sci. 2018;9(1):7-10. doi:10.15171/jlms.2018.02

13. Moravvaej H, Daneshvar L, Saeedi M, Barzegar MR. Treatment of a Pigmented Hypertrophic Scar by LowLevel Laser Therapy (LLLT): a case report. J Lasers Med Sci. 2010;1(1):35-38.

14. Mizutani K, Musya Y, Wakae K, et al. A clinical study on serum prostaglandin E2 with low-level laser therapy. Photomed Laser Surg. 2004;22(6):537-539. doi:10.1089/ pho.2004.22.537

15. Gao X, Xing D. Molecular mechanisms of cell proliferation induced by low power laser irradiation. J Biomed Sci. 2009;16:4. doi:10.1186/1423-0127-16-4

16. Bolognani L, Volpi N. Low power laser enzymology: Reactivation of myosin ATPase by GaAs an HeNe lasers. In: Passarella S, Quagliariello E, eds. Basic and Applied Research in Photobiology and Photomedicine. Bari, Italy: University of Bari; 1991:315-38.

17. Sefati N, Norouzian M, Abbaszadeh HA, et al. Effects of bone marrow mesenchymal stem cells-conditioned medium on tibial partial osteotomy model of fracture healing in hypothyroidism Rats. Iran Biomed J. 2018;22(2):90-98.

18. Freidouni M, Nejati H, Salimi M, et al. Evaluating glucocorticoid administration on biomechanical properties of rats' tibial diaphysis. Iran Red Crescent Med J. 2015;17(3):e19389.

19. Soleimani H, Amini A, Taheri S, et al. The effect of combined photobiomodulation and curcumin on skin wound healing in type I diabetes in rats. J Photochem Photobiol B. 2018;181:23-30. doi:10.1016/j.jphotobiol.2018.02.023

20. Hopkins JT, McLoda TA, Seegmiller JG, David Baxter G. Low-level laser therapy facilitates superficial wound healing in humans: a triple-blind, sham-controlled study. $J$ Athl Train. 2004;39(3):223-229.

21. Pouriran R, Piryaei A, Mostafavinia A, et al. The effect of combined pulsed wave low-level laser therapy and human bone marrow mesenchymal stem cell-conditioned medium on open skin wound healing in diabetic rats. Photomed Laser Surg. 2016;34(8):345-354. doi:10.1089/ pho.2015.4020

22. Son Y, Cheong YK, Kim NH, Chung HT, Kang DG, Pae HO. Mitogen-activated protein kinases and reactive oxygen species: how can ROS activate MAPK pathways? J Signal Transduct. 2011;2011:792639. doi:10.1155/2011/792639

23. Arakaki N, Yamashita A, Niimi S, Yamazaki T. Involvement of reactive oxygen species in osteoblastic differentiation of MC3T3-E1 cells accompanied by mitochondrial morphological dynamics. Biomed Res. 2013;34(3):161-166.

24. Mohsenifar Z, Fridoni M, Ghatrehsamani M, et al. Evaluation of the effects of pulsed wave LLLT on tibial diaphysis in two rat models of experimental osteoporosis, as examined by stereological and real-time PCR gene expression analyses. Lasers Med Sci. 2016;31(4):721-732.

25. Kassem R, Liberty Z, Babaev M, Trau H, Cohen O. Harnessing the skin-thyroid connection for wound healing: a prospective controlled trial in guinea pigs. Clin Exp Dermatol. 2012;37(8):850-856. doi:10.1111/j.13652230.2012.04456.x

26. Safer JD, Crawford TM, Holick MF. Topical thyroid hormone accelerates wound healing in mice. Endocrinology. 2005;146(10):4425-4430. doi:10.1210/en.2005-0192 
27. Tarameshloo M, Norouzian M, Zarein-Dolab S, Dadpay M, Gazor R. A comparative study of the effects of topical application of Aloe vera, thyroid hormone and silver sulfadiazine on skin wounds in Wistar rats. Lab Anim Res. 2012;28(1):17-21. doi:10.5625/lar.2012.28.1.17

28. Asghari M, Kanonisabet A, Safakhah M, et al. The effect of combined photobiomodulation and metformin on open skin wound healing in a non-genetic model of type II diabetes. J Photochem Photobiol B. 2017;169:63-69. doi: 10.1016/j.jphotobiol.2017.03.002.

29. Erdogan M, Ilhan YS, Akkus MA, et al. Effects of L-thyroxine and zinc therapy on wound healing in hypothyroid rats. Acta Chir Belg. 1999;99(2):72-77.

30. Brown GL, Nanney LB, Griffen J, et al. Enhancement of wound healing by topical treatment with epidermal growth factor. N Engl J Med. 1989;321(2):76-79. doi:10.1056/ nejm198907133210203

31. Lorenz H, Longaker MT. Wound healing: repair biology and wound and scar treatment. Plastic Surgery. 2006;1:209232.

32. Goldman R. Growth factors and chronic wound healing: past, present, and future. Adv Skin Wound Care.
2004;17(1):24-35.

33. Rosko AJ, Birkeland AC, Bellile E, et al. Hypothyroidism and wound healing after salvage laryngectomy. Ann Surg Oncol. 2018;25(5):1288-1295. doi:10.1245/s10434-0176278-4

34. Lennox J, Johnston ID. The effect of thyroid status on nitrogen balance and the rate of wound healing after injury in rats. Br J Surg. 1973;60(4):309.

35. Viegas VN, Abreu ME, Viezzer C, et al. Effect of low-level laser therapy on inflammatory reactions during wound healing: comparison with meloxicam. Photomed Laser Surg. 2007;25(6):467-473. doi:10.1089/pho.2007.1098

36. Busnardo VL, Biondo-Simoes ML. [Effects of low-level helium-neon laser on induced wound healing in rats]. Rev Bras Fisioter. 2010;14(1):45-51.

37. Allendorf JD, Bessler M, Huang J, et al. Helium-neon laser irradiation at fluences of 1,2 , and $4 \mathrm{~J} / \mathrm{cm}^{2}$ failed to accelerate wound healing as assessed by both wound contracture rate and tensile strength. Lasers Surg Med. 1997;20(3):340-345.

38. Mancini A, Di Segni C, Raimondo S, et al. Thyroid hormones, oxidative stress, and inflammation. Mediators Inflamm. 2016;2016:6757154. doi:10.1155/2016/6757154 